\title{
The Construction of Adolescence on Social Media
}

\author{
Samuel Danso \\ Department of Communication Studies, University of Cape Coast, Ghana
}

\begin{abstract}
The recent use of internet enabled technology has significantly impacted the way adolescents use social media. Once they are confined to a computer, laptop or mobile phone with internet accessibility, these adolescents are able to explore over a wider range on social media. However, attention has not been drawn to the impact of social media on adolescence. This research proposal examines the construction of adolescence on social media. It also seeks to identify the effects of social media on social behavior and academic performance of students in Senior High Schools with a focus on Oti Boateng Senior High School in Koforidua. In this research study, I intend using the Social Learning Theory and Uses of Gratification Theory as my theoretical framework. The study would employ quantitative method for data collection involving questionnaire administration.
\end{abstract}

Keywords: Adolescence, Social media, Facebook, Questionnaire, Academic Performance

DOI: $10.7176 / \mathrm{JEP} / 10-9-08$

Publication date:March $31^{\text {st }} 2019$

\section{Introduction}

In recent years, the advancement of technology from analogue to digital has immensely changed the way in which people communicate in our society. The ability to exchange information using modern technologies has changed the way adolescence interact, learn and socialized. Social media networking as an effective tool has become part of the daily life experience for an increasing number of adolescence. This is especially evident in the way in which social media platforms such as instant messaging, WhatsApp, and social networking functions now. Adolescents are voracious internet and social media users who share and express self-created contents and opinions online. Concerns have been expressed about the amount of time that these 'digital natives' spend surfing the internet. O'Keeffe \& Clarke-Pearson (2011), opine that because of their limited capacity for self-regulation and susceptibility to peer pressure, children and adolescents are at some risk as they navigate and experiment with social media. Nonetheless, they were silent on the numerous benefits that adolescence derive from the social media. The role of social media on them cannot be overemphasized.

Tartari (2014), also shows that the foundation of social media is the social interaction, which gives the participants the possibility to share opinions, thoughts, and knowledge in a global forum where time and place are insignificant. Social media, through its interactive platform enables adolescence to communicate with other members in building social relationship.

\section{Statement of the Problem}

The advancement in modern technology in the use of the internet has greatly enlightened adolescence to a wider world of greater possibilities and expectations. The wealth of information available to these adolescence because of the internet and social media has exposed them to an exciting future coupled with bigger achievements.

However, a lot of attention has not been drawn to the impact of social media on adolescence even though it serves as gate way of accessing numerous information.

\section{Objectives of the Study}

This research thus examines how teenagers at Oti Boateng Senior High School (OBOSS) in Koforidua interact when exposed to the social media. It also investigates how teenagers at Oti Boateng Senior High School use social media as an interactive platform in building social relationship and sharing of information. Finally, it explores the effects that social media pose on adolescence.

\section{Research Questions}

The research will seek to answer the following questions:

1. How do students of OBOSS interact on social media?

2. What effects do social media have on the behaviour change of OBOSS students?

\section{Significance of the Study}

The findings of this study will provide useful information on why a number of teenagers have taken to the various social media platforms and the effects on behavioral changes. It will also assist policy makers in various sectors of the government when taking decisions concerning the youth. For instance, educational sector curriculum developers will be informed when developing curriculum for the youth. 


\section{Literature Review}

Social media have gained recognition in terms of growth and fame worldwide. Owusu-Acheaw and Larson (2015), reiterate that social media has exploded as a category of online discourse where people create content, share it, bookmark it and network at a prodigious rate. In order to understand what goes on in the social media, many researchers are now interested in learning more about these social media platforms and their effects on the community. Adolescence are the leading and most fanatic of these social media platforms. Using social media websites is among the most common activity of today's children and adolescents. O'Keeffe and Clarke-Pearson (2011), expound that any Website that allows social interaction is considered a social media site, including social networking sites such as Facebook, Myspace, Instagram and Twitter.

Junco et al. (2010), posit that social media is a collection of internet websites, services, and practices that support collaboration, community building, participation, and sharing. Users typically access social media services via web-based technologies on desktop computers, and laptops, or download services that offer social media functions to their mobile devices. When engaging with these services, users can create highly interactive platforms through which individuals, communities, and organizations can share, co-create, discuss, and modify usergenerated content or pre-made content posted online. The growing dimension on the use of social media among second cycle students cannot be over emphasized. Social media through its interactive platform enable users to communicate with other members in building social relationship, sharing information and knowledge related to the needs and activities in society. This increasingly ubiquitous access to the internet can be positive; for example, people of all ages are turning to this medium for information on sexual education and sexual health (Barack \& Fisher, 2001).

Adolescents in particular, spend enough time interacting in their social lives. They often lack the risk attenuation needed to discern and manage online dangers and content in safe and healthy ways (Delmonico \& Griffin, 2008). The use of social media by teenagers occur at the same time with their developing identity and sexuality. Social networking is a way that helps adolescents feel as though they belong to a community by establishing connection with friends and even strangers. However, due to its increase in popularity, most people have expressed concerns about the effects on academic performance. They are of the view that students who spend more time on these social media sites study less and score low marks. This could partly be attributed to the fact that most adolescents with Facebook or other social networking accounts, may be engaging in instant messaging constantly while they are carrying out their tasks. As adolescents use of internet increases, it is important to acknowledge the systemic impact of this medium, and specifically exposure to pornographic stimuli on adolescent development.

Adolescent development involves critical and significant changes across a multitude of domains: physical, emotional, cognitive, social, spiritual, and sexual. Consequently, adolescents are considered as one of the most susceptible audiences to sexually explicit content as they browse the internet. Recent research suggests that there is a relationship between adolescents who are exposed to internet pornography and the acquisition of a variety of sexual beliefs.

Peter and Valkenburg (2009), argue that sexually explicit material can offer numerous sexual attitudes to viewers, and that these beliefs may differ from those instilled in adolescents by their families and schools. They expound that conflict in sexual beliefs, is attributed to increased sexual uncertainty. They emphasized that the dominant adult discourse of adolescent sexuality, focuses much on media effects on sexual behavior and neglects other important aspects of adolescents' sexuality that may be affected by sexual media content. One of these aspects may be adolescents' sexual preoccupancy with sexual issues. Focusing on adolescents' sexual preoccupancy as a result of their exposure to sexualized media environment may not only help us to deepen our knowledge about the implications of adolescents' exposure to a sexualized media environment but generally, it may also inform approaches that look for a broader view of adolescent sexuality in a media-saturated age.

Peter and Valkenburg suggest that as adolescents are more frequently exposed to sexually explicit materials, their perception of the social realism and the utility of sexually explicit material increases. They defined sexually explicit materials as content that depicts sexual activities in unconcealed ways, often with arousal of genitals and of oral, anal, or vaginal penetration. Their study also suggests that the greater adolescents' perceptions of social realism and utility of sexually explicit material, the greater their instrumental attitudes toward sex. Some of these adolescence engage in sexting to satisfy their desires. Sexting can be defined as sending, receiving, or forwarding sexually explicit messages, photographs, or images via cell phone, computer, or other digital devices. In some cases, additional consequences including school suspension for perpetrators and emotional distress with accompanying mental health conditions bedevil these victims. In many circumstances, however, the sexting incident is not shared beyond a small peer group or a couple and is not found to be distressing at all.

Concerns are raised about the pace of sociological and technological change. There are suggestions that social media environment is impacting on adolescents' inherent need to develop dependency on strong and robust peer support. Nonetheless, a qualitative study conducted by LÖfgren-Märtenson and Mänsson (2010), contradicts Peter and Valkenburg's findings. LÖfgren- Märtenson and Mänsson collected data from an adolescent population of 51 
in Sweden. These data indicated that majority of the participants were able to distinguish between the fantasy of sexually explicit material and real-life sexual interaction. However, the research participants acknowledged that the ideals and pornographic scripts presented in sexually explicit material do influence young people.

Additional research has shown that exposure to sexually explicit material is a normative experience among adolescents who are following traditional developmental trajectories regarding sexual curiosity. As their Internet use increases, it is important to understand the systemic impact of this medium, and specifically exposure to pornographic stimuli, on adolescent development. Adolescent development, for the purposes of this research proposal, is understood to involve critical and significant changes across a multitude of domains including physical, emotional, cognitive, social, spiritual, and sexual. Consequently, adolescents are considered one of the most susceptible audiences to sexually explicit content. While it is developmentally normal for adolescents to have sexual curiosity, the extent of easy, free, and unmonitored access to pornography on the internet needs to be examined critically.

\section{Theoretical Framework}

In this study, I intend using two theories in the theoretical framework. They are the Social Learning Theory and Uses of Gratification Theory. These theories are significant for my research work because they portray how adolescence learn from models and the ways in which the public consume media.

\section{Social Learning Theory of Identification}

The Social Learning Theory of Identification is a process whereby a person patterns his/her thoughts, feelings or actions after another person who serves as a model. Hanna et al. (2013), posit that individuals learn much of their behaviour by observing others. In social learning theory, an identification event is defined as the occurrence of similarity between the behavior of a model and another person under conditions where the model's behavior has served as the determinant cue for the matching responses.

Brauer and Tittle (2012), argue that in social learning theory, people learn deviant behaviour in the same way that they learn non-deviant behaviour. Although the matching process frequently involves reproduction of specific patterns of behavior, in many instances a common attribute abstracted from diverse responses is modelled. It should be noted that both the characteristics of the behavior and its antecedents are the principal defining properties of identification. Based on this theory, it is evident that students stand greater chance of reproducing observed behavior on social media. They are likely to practice these behaviour in their everyday life.

\section{Uses and Gratification Theory}

Uses and gratification theory study ways in which the public consumes media. This theory states that consumers use the media to satisfy specific needs or desires. Lopez et al. (2017), clarify that people use media because they derive specific gratifications from its consumption. Many people use the internet for entertainment, finding out information, communicating or to pursue self-expression. Each of these gratifies a particular need, and the needs determine the way in which media is used. A typical uses and gratification study explore the motives for media consumption and the consequences associated with the use of that media. By examining the motives behind the consumption of a particular form of media, researchers can better understand both the reasons for that medium's popularity and the roles that it plays in society.

A study of the motives behind a given user's interaction on Facebook, for example, could explain the role that Facebook takes in society and the reasons for its appeal. As the internet penetration keeps widening and social media platforms continue proliferating, there is little knowledge on why and how people use these media sites and that forms the basis of the Uses and Gratifications Theory. Students are described as the major users of social media. Mir (2017), explains that social network sites have emerged as a common place for social interactivity and communication in cyberspace. Therefore, the Uses and Gratification Theory is an ideal theory to identify and analyze the reasons why adolescence use social media.

\section{Methodology}

The study is being undertaken to investigate the construction of adolescence on social media with particular emphasis on Facebook and Twitter. It also investigates whether these social media tools affect the academic performance of adolescence positively or negatively as well as its effect on their social behaviour. Knowles et al. (2014), emphasize that social media can be a powerful tool for teens to connect with each other, but it is not without the opportunity for significant risk-taking behaviours. My primary source of information would be students from Oti Boateng Senior High School (OBOSS). OBOSS was established in 1991 to enhance Government commitment in providing Secondary Education to students in and around Koforidua Municipality. The school has a general student population of about 2,800 people. I decided to choose the research site due to proximity, academic performance of the students and their high rate of using social media platforms.

Out of the total population of 2,800 students, 200 students would be selected using purposive sampling 
technique from all the various Departments. Purposive sampling, a non-probability method would be chosen for the selection of the sample size. Purposive sampling is a kind of focus sampling approach which determines who should be the participants in the research. It is a sampling technique that I would rely on when choosing members of the population to participate in the study. Averagely, the ages of the respondents range from 13-18. These would include the general students and their respective Class Prefects. This measure would ensure that the targeted population in the school is fully represented. Haidari et al. (2016), explain that sex and gender differences are often overlooked in research design, study implementation, scientific reporting, as well as in general science communication. This oversight limits the generalizability of research findings and their applicability to clinical practice. In view of this, gender status would also be considered as female students would form half of the total population to be selected. I would choose quantitative method for an in-depth and reliable study. The approach would also be chosen to arrive at clear and publishable results that would be relevant to existing literature. Quantitative methods express the assumptions of a positivist paradigm which holds that behaviour can be explained through objective facts. This method maintains that in this world, there is objective reality which can be observed and measured. It is a kind of research that uses numbers.

The survey method would be used to solicit data and information from the sample of students of OBOSS during instructional hours of the first semester of 2019 academic year. I would design questionnaire to collect the data appropriate for the study. Survey method is a quantitative approach to the study of the social processes within a well-defined area at a given time through one or more institutions by means of an interview schedule or a questionnaire.

Before the data collection, I would seek permission from the School's administration a week prior to the exercise. Ethically, confidentiality and privacy would be considered. Participants would be informed about the data collection process including the use of recording peripherals such as mobile phones and cameras. Thus, their consent would be sought. Also, respondents would be briefed on the purpose of the study, expected duration and the procedure. Anonymity of the respondents would also be considered. Their original names would not be used in the research.

To improve upon the reliability and validity of the questionnaire, it would be pre-tested in Pope John's Seminary Senior High School at Koforidua because it is closer to me. The results that would be obtained will help design the questionnaire to suit the expected purpose of the study. Twenty two (22) research questions would be culled from the main objectives to be administered to the respondents. They would include demography, knowledge on social media and the impact on behavioural change. Respondents would be given between 20 and 30 minutes to complete the questionnaires.

\section{Limitations/Challenges}

Even though I would seek permission prior to the visit, it is anticipated that accessibility would be a constraint because one-week prior notice would not be enough for the school's administration. Also, it would be anticipated that the respondents would find it difficult in providing the necessary details on the questionnaire for fear of being exposed to their parents.

Finally, time would also be a constraint to both the respondents and myself.

\section{References}

Barak, A., \& Fisher, W. A. (2001). Toward an Internet-driven, theoretically-based innovative approach to sex education. Journal of Sex Research, 38, 324-332.

Brauer, J.R., \& Tittle, C.R. (2012). Social learning theory and human reinforcement. Sociological Spectrum, 32(2), $157-177$

Delmonico, D. L., \& Griffin, E. J. (2008). Cybersex and the E-Teen: What marriage and family therapists should know. Journal of Marital and Family Therapy, 34(4), 431-444.

Hanna, R.C., Crittenden, V.L., \& Crittenden, W.F. (2013). Social learning theory: a multicultural study of influences on ethical behaviour. Journal of Marketing Education, 35(1), 18-25.

Heidari, S., Babor, T.F., De-Castro., Tort, S., \& Curno, M. (2016). Sex and gender equity in research: rationale for the SAGER guidelines and recommended use. Research Integrity and Peer Review, (1)2, 1-9.

Junco, R., Heibeiger, G., \& Loken, E. (2010). The effect of twitter on college student engagement and grades. Journal of Applied Development Psychology, 30(3), 227-238.

Knowles, M., Lee, S.H., O'Riondan, M.A., \& Lazebnik, R. (2014). Risk of social media for teens in an urban setting. Global Pediatric Health, 1, 1-4.

Lopez, C., Hartmann, P., \& Apaolaza, V. (2017). Gratifications on social networking sites: the role of secondary school students' individual differences in loneliness. Journal of Educational Computing, 0(0), 1-25.

Märtenson, L.L., \& Mänsson, S.A. (2009). Lust, love, and life: a qualitative study of Swedish adolescents' perceptions and experiences with pornography. Journal of Sex Research, 47(6), 568-579.

Mir, I.A. (2017). Users on social network sites-flight from reality and its effects on acceptance of social network 
advertising: a gratification perspective. Journal of Creative Communication, 12(2), 98-121.

O'Keeffe, G. S., \& Clarke-Pearson, K. (2011). The impact of social media on children, adolescents, and families. Pediatrics, 127(4), 800-804.

Owusu-Acheaw, M., \& Larson, A.G. (2015). Use of social media and its impact on academic performance of tertiary institution students: a study of students of Koforidua Polytechnic. Journal of Education and Practice, 6(6), 94-95

Peter, J., \& Valkenburg, P.M. (2009). Adolescents' exposure to sexually explicit internet material and sexual satisfaction: a longitudinal study. Human Communication Research, 35(2), 171-194.

Tartari, E. (2014). Benefits and risks of children and adolescents using social media. Educational and Social Research, 11(13), 321-332.

\section{Questionnaire}

Part I - Demography (Please kindly provide the following details).

1. How old are you?

2. Which course are you pursuing?

3. What is your class?

4. Gender: Male [ ] Female [ ]

Part II - Knowledge on Social Media (Please kindly indicate your response by ticking either Yes or No in the bracket provided).

5. Do you have knowledge on social media networking?

6. Do you use any social media network?

7. Do you have internet in your school and home?

8. Do you use mobile phone in accessing the internet?

9. Do you browse the internet for educational materials?

10. Do you evaluate the content that you post on social media?

11. Do you have Facebook and Twitter accounts?

12. Have you ever regretted posting pictures on Facebook?

$\begin{array}{ll}\text { Yes [ ] } & \text { No [ ] } \\ \text { Yes [ ] } & \text { No [ ] } \\ \text { Yes [ ] } & \text { No [ ] } \\ \text { Yes [ ] } & \text { No [ ] } \\ \text { Yes [ ] } & \text { No [ ] } \\ \text { Yes [ ] } & \text { No [ ] } \\ \text { Yes [ ] } & \text { No [ ] } \\ \text { Yes [ ] No [ ] } & \text { No } \\ \text { Yes [ ] No [ }\end{array}$

13. Do you practice what you see on Facebook and Twitter pages?

Yes [

Part III - Effects of social media (Please indicate your response by choosing the appropriate response).

14. Use of social media networks improves academic performance.

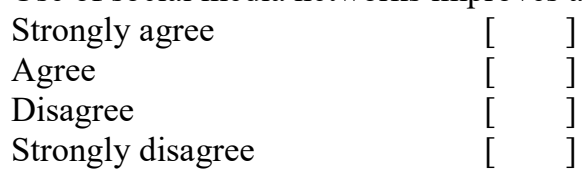

15. Use of social media networks have positive impact on social behavior.

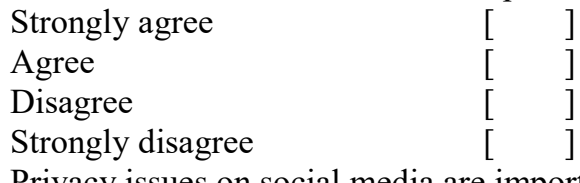

16. Privacy issues on social media are important.

Strongly agree

Agree

Disagree

Strongly disagree

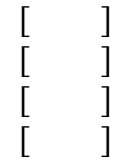

17. Social media helps in building relationships

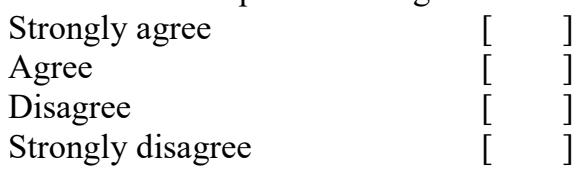

18. Adolescents should be banned from visiting social media sites Strongly agree

Agree

Disagree

Strongly disagree

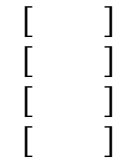

19. How many times do you visit social media sites in a day?

1 [ ] $2[$ ] $3[$ ] $4[$ ] 
20. How many hours do you spend on the internet in a day?

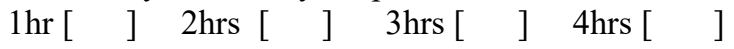

Part IV - Effects of social media (Please kindly provide the necessary answer)

21. Outline any four (4) social media sites that you normally visit on the internet.
a.
b.
c.

d.

22. Write down any two effects of social media on adolescents.

a.

b. 